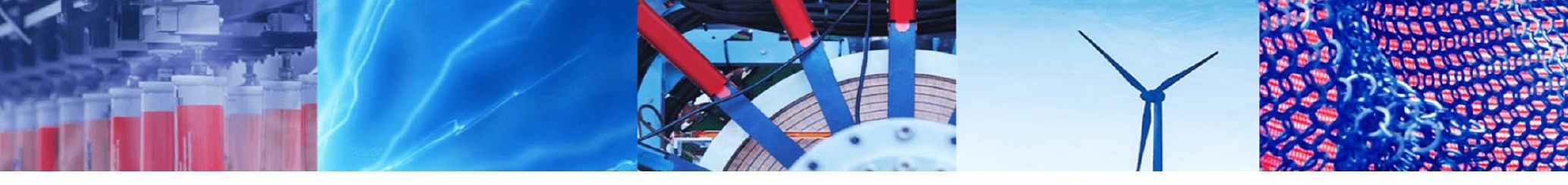

Research Article

\title{
Relationship between environmental factors and water pipe failure: an open access data study
}

\author{
Nazila Hekmati ${ }^{1} \cdot$ Md Mizanur Rahman $^{1,2} \cdot$ Nima Gorjian $^{1,3} \cdot$ Rameez Rameezdeen $^{1} \cdot$ Christopher W. K. Chow $^{1,2}$ ID
}

Received: 2 May 2020 / Accepted: 22 September 2020 / Published online: 10 October 2020

(c) Springer Nature Switzerland AG 2020

\begin{abstract}
The present study provides a proof-of-concept data collection methodology for water pipes failure from publicly available (open) data sources and identification of the common causes of water pipes failure in a water supply network, which may be automated with artificial intelligent (AI) methodology. Using Adelaide (South Australia) as the location of our case study, open source databases, such as pipe failures of SA Water (Twitter feeds), data from the Bureau of Meteorology, Adelaide Metropolitan soil data reports, etc., have been used to identify pipe failure locations, which was then correlated with the environmental factors e.g. soil type, monthly rainfall pattern, etc. The results were compared with the SA Water's renewal program to validate the methodology introduced by this research. The results confirmed SA Water's asset management system is very effective in managing its linear assets with the areas focused on the water main replacement program matched well with the pipe failure locations. This not only validated the methodology introduced by this research is capable to identify the high-risk pipe failure areas but also facilitated linkage between government and public agencies externally via their open access data which may complement their core services.
\end{abstract}

Keywords Water utilities · Asset management - Data and information - Open data access · Pipe failures - Soil reactivity

\section{Introduction}

Water utilities are asset-intensive organisations and as such, the assets need to be managed efficiently and effectively to achieve the required service levels at an affordable (lowest possible) price for the customers. Asset management is an essential component of any water utility, which helps to understand where and when the investment is needed and how the budget should be allocated. Despite the huge yearly investment, water mains failure is one of the significant issues in water industries' infrastructure management. The impact of a water pipe failure can be very costly to a water utility, it is not only the financial cost of repair/replacement but also the negative visibility and damage to its reputation. Maintenance decision is made based on several factors such as; previous failure history, customer feedback and restrictions in the network including low flow. Usually, by checking the frequency of pipe failure can alert the water utility asset planners/managers of imminent failures in a region that should be considered as a priority action in the asset management system. The use of preventive actions for effective control of pipe failure is one of the options to provide water services in a more reliable and affordable way to the customers. The use of data analytics to understand the factors related to pipe failures can be used to inform decisions for a better asset management program, particularly for the renewal program with a balance between cost and risk [1-5].

The water supply system in South Australia is a complex network of 26,800 kilometres of pipe, including 9000

Christopher W. K. Chow, christopher.chow@unisa.edu.au | ${ }^{1}$ UniSA STEM (Science, Technology, Engineering and Mathematics), Scarce Resources and Circular Economy (ScaRCE), University of South Australia, Adelaide, SA 5000, Australia. ${ }^{2}$ UniSA STEM (Science, Technology, Engineering and Mathematics), Future Industry Institute, University of South Australia, Adelaide, SA 5000, Australia. ${ }^{3}$ South Australian Water Corporation, Adelaide, SA, Australia. 
kilometres in Adelaide (capital city of South Australia) metropolitan area. The number of water main failures in Adelaide, South Australia, has been in decline since 2014, which indicates the devoted efforts of SA Water, the state's water utility, to improve the system. Generally, the average age of water mains is about 50 years [6]. In Adelaide, half of the water supply infrastructure is less than 50 years old, however, out of the other half about $18 \%$ is more than 80 years old. This requires a huge yearly investment to maintain the system by a properly managed water mains renewal program [7].

Wang et al. [8] suggested that the behaviour of pipes can be explained based on their failure statistics and environmental factors (dynamic features) with the assumption that pipes with similar characteristics and working environment will experience similar deterioration patterns. The environmental factors related to pipe failure are: soil type and soil reactivity, weather (temperature variation), rainfall and location [9-12]. Rajani et al. [13] reported a water pipe failure study that showed a surge in soil water content along with temperature drop caused the increase in pipe failure during winter. Physical factors such as pipe material, diameter and installation time can also have a major impact on pipe failure. Generally, pipe failure is associated with a combination of these factors [14-16]. All these attributes can individually affect the life expectancy of an underground pipe network and a greater overall impact on the pipe life expectancy would be expected when these attributes combined together.

This study addresses this big issue - pipe failure - that the water utilities are constantly facing in their day-to-day operations. It opens new research opportunities to apply new tools to study the impact of environmental factors on pipe failures which could reliably predict the location of a failure before it happens. While failure prediction is the aim, lack of reliable data for such prediction hampers many research efforts. To fill this gap, the present study provides a data collection methodology from open source databases to identify the common causes of water pipes break in an urban water supply network. The objective is to identify the common causes of water pipe failure in Adelaide by analysing past pipe failure. The specific objectives of this work are: (1) Identify the factors associated with waterpipe failures in Adelaide; (2) ascertaining data needs to predict such pipe failure; and (3) evaluating the usefulness of open data sources for such prediction. Based on the findings, several recommendations are proposed to improve the planning of future asset maintenance and renewal programs of the subject water utility, SA Water.

\section{Methodology}

The pipe failure data used in this study were collected from an open access source, twitter, to evaluate their suitability and reliability to develop an up-to-date database. In this proof-of-concept study, pipe failure data were collected manually from SA water twits, however, an automated data collection for a larger project is possible via a Twitter application programming interface (API) as discussed in Kim et al. [17], which was beyond the scope of this study. In addition, this study also collected geographical and meteorological data from open access sources and also discusses data processing, interpretation and visualisation (display) along with a suite of software. This also discusses the process of overlaying these data on the Adelaide map to communicate via meaningful image/action plan with stakeholders to locate where actions need to be taken.

The following databases and software were used in this study:

- SA Water Twitter

- National Map (https://nationalmap.gov.au/2

- SA Map Viewer (http://location.sa.gov.au/viewer/)

- SA Water Metropolitan Water Main Replacement Program and SA Water Geographical Information System (GIS) maps using ArcGIS software (http://sawat er.maps.arcgis.com)

- South Australian Resources Information Gateway (SARIG) Map Metropolitan Soil Data

- Bureau of Meteorology

This methodology requires communication, linkage and data sharing between different government and private agencies, which may not be readily available at this stage but can be achieved externally via open access data sources. It is envisaged that validation of this proofof-concept, may trigger a significant research interest on automating the above processes.

\section{(a) SA Water Twitter}

SA Water has joined Twitter in May 2011 to form a close connection with its customers and to give a more convenient and quicker response to customer complaints (see Fig. 1). It is a two-way communication between the SA Water and its customers-Tweet is used to inform all pipe failures, updates, upgrades, diggings and excavations, and all the capital projects in Adelaide which can affect the water mains/water supply.

A total number of 123 failure events were captured from SA Water Twitter feeds along with information of 


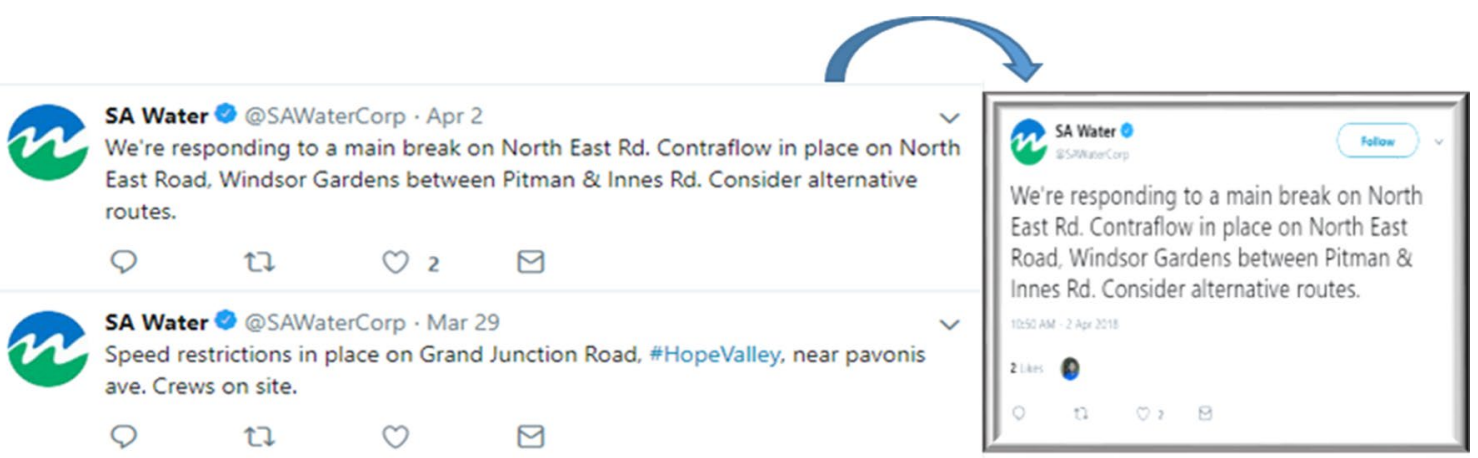

Fig. 1 An example of the SA Water Twitter screen

the date and the location of the failure, the street name and the day of repair. This information was collected for one year of the study period (from April 2018 backward to April 2017) and was recorded in an Excel file as the main database for this study.

\section{(b) National map}

To have an accurate location of the failure as geographical representation, National Map [18] was used to translate the address into Latitude and Longitude coordinates. Then, the Latitude and Longitude coordinates of the locations were recorded to the Excel database.

\section{(c) Location SA map viewer}

The main characteristics at the location and the history of the pipe regarding installation date can be obtained from SA Map Viewer [19]. This is a very practical tool which brings location-based data together in one website with the inclusion of different layers for different end-users. A layer can be chosen and required information for that location can be shown in a display box (Fig. 2). The pipe diameter and installation date of pipes for the 123 failures under consideration were added to the Excel database.

(d) SA Water metropolitan water main replacement program and SA Water ArcGIS maps

To confirm the data collected from the "Location SA Map viewer" and to add more data, SA Water metropolitan water mains replacement program was used. This

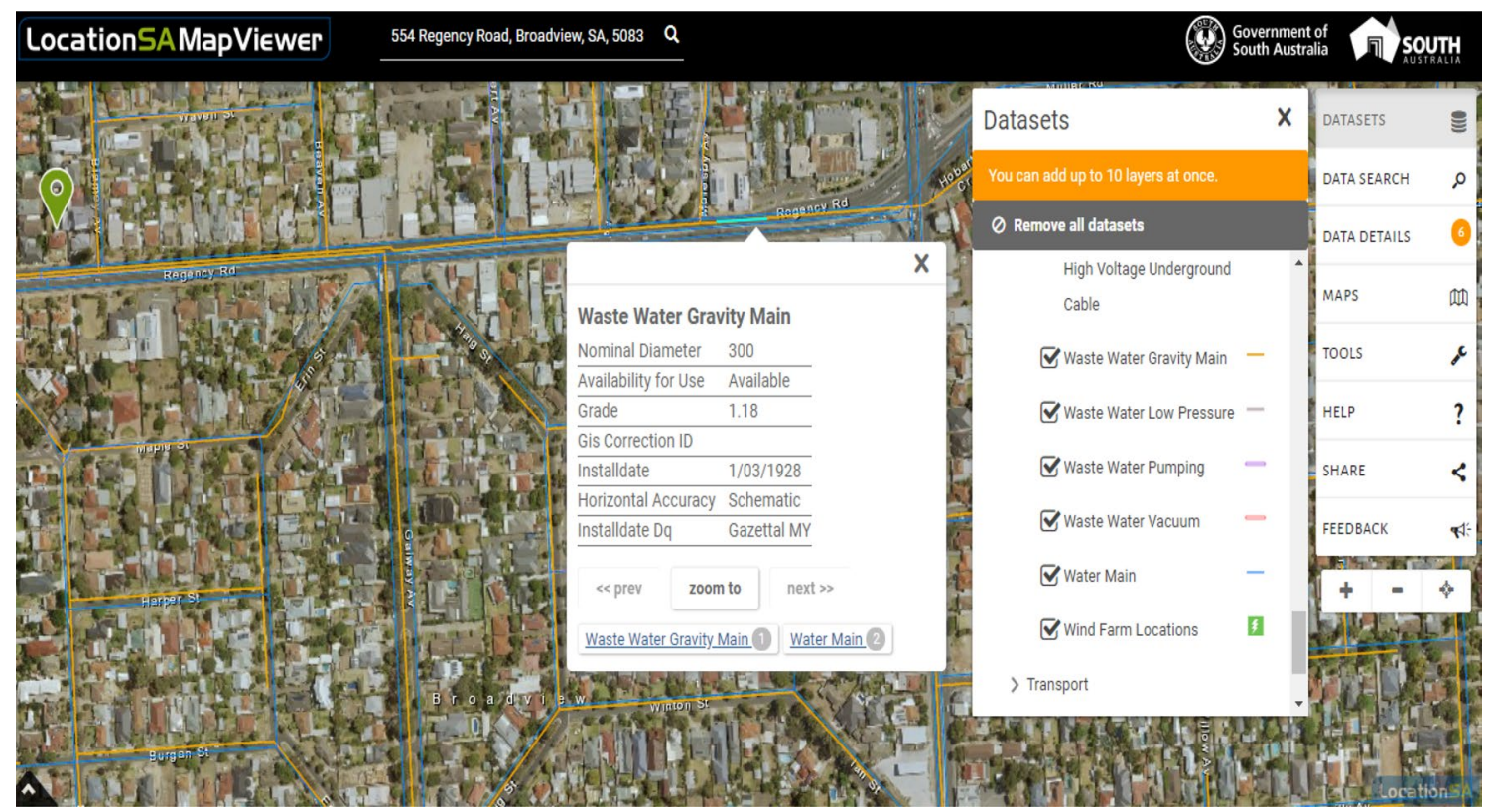

Fig. 2 Location SA map viewer [19] 
program is an interactive map that allows the customers to browse water mains network and view pipe replacements, planned replacements and future focus areas (Fig. 3).

The planned future work on this program has been highlighted in red, so the customer can easily identify the location of the work planned in future with some information on the intended activities. The key distribution network information, such as, the diameter of the pipe and installation date, can be obtained, and even the number of customers are currently connected to that main can be found if the location is in the planned focus area. All this information was added to the Excel database for analysis.

\section{(e) SARIG maps: metropolitan soil data}

To discuss the soil type of different regions on the map, there was a need to get the shapefile (a file format contains geospatial vector data format for GIS software) for Adelaide metropolitan soil data. This information has been obtained from South Australian Resources Information Gateway (SARIG) [19] who provides online access to the best available information on soil and land resources in a consistent format across Australia. This map has the complete information about the soil code and soil type in each region. The shapefile was added as a layer of information to the main database layer in ArcGIS software for further analysis.

\section{Results and discussions}

\subsection{Setup of ArcGIS by using failure locations}

The data have been recorded in Excel format according to the failure events. Figure 4 shows the locations of the failures and main factors known to be related to pipe failures.

As explained in the Methodology section, the failure location data were converted to ArcGIS format and then plotted on the Adelaide map as shown in Fig. $5 \mathrm{a}$.

By using the base map function, the layer format of the map was changed to imagery with labels that gave a better view of the suburbs and corresponding failure data points. The map on Fig. $5 \mathrm{~b}$ shows that most of the data points are concentrated in the Central Business District (CBD) and the North East of Adelaide. Adelaide $\mathrm{CBD}$ is the most densely populated area in Adelaide with many commercial and residential households a very old infrastructure network compared to suburbs. Considering that, it is a logical observation of expecting high failure numbers even without involving soil factors and other physical characteristics of pipes. Regarding the Eastern suburbs, the soil type has played a major role as explained in more detail later in this paper.

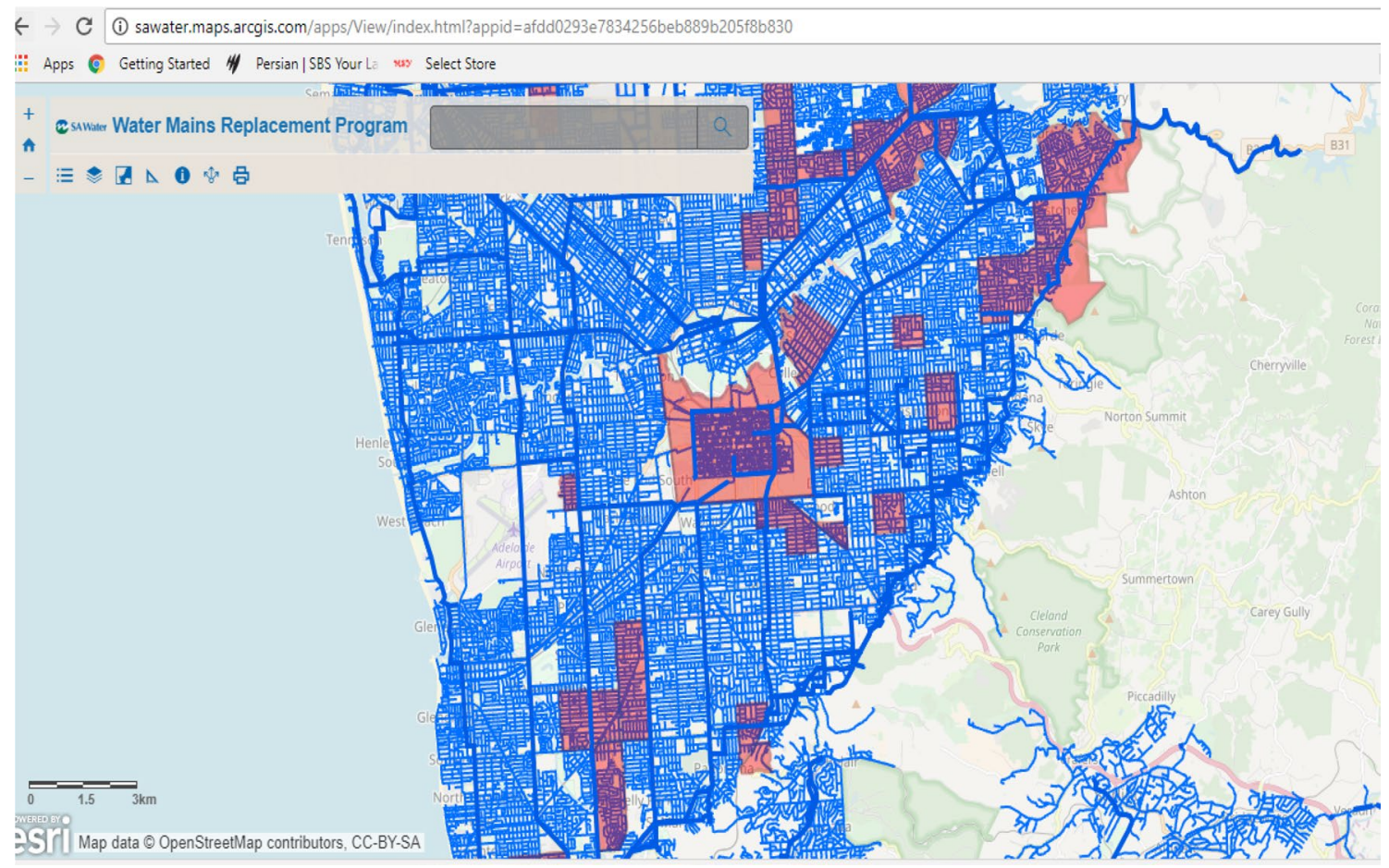

Fig. 3 A screenshot of the water main replacement program of 2018. Red highlighted are areas for future work 


\begin{tabular}{|c|c|c|c|c|c|c|c|c|c|c|}
\hline & Location & $\begin{array}{l}\text { SA Water burst } \\
\text { record }\end{array}$ & Date & Location & Location & Issue & $\begin{array}{l}\text { Result of } \\
\text { maintenance }\end{array}$ & Diameter & Installation & $\begin{array}{l}\text { Type of } \\
\text { water }\end{array}$ \\
\hline & 4-2 Glen 0smond Rd & Glen osmond\& greenhil, eastwoo & $25 / 03 / 2018$ & $34.94056^{\circ} \mathrm{S}$ & $138.61587^{\circ} \mathrm{E}$ & Main repair & completed 27 March & $145 \mathrm{~mm}$ & 1938 & Drinking water \\
\hline & Eastwood SA 5063 & & & & & & & & & \\
\hline & $-34.940645,138.615513$ & \multirow[b]{2}{*}{ Downer Ave, Montala Dr, Belair } & & & & & & & & \\
\hline & Monalta Dr & & $25 / 03 / 2018$ & $35.00346^{\circ} \mathrm{S}$ & $138.62463^{\circ} \mathrm{E}$ & water main break & 27-Mar & $\mathrm{m} / 300 \mathrm{~mm} / 65$ & $1968 / 1940 / 1964$ & Drinking water \\
\hline & Belair SA 5052 & & & & & & & & & \\
\hline & $-35.003483,138.624709$ & & & & & & & & & \\
\hline & $\Delta 6$ & Sir Donald Bradman Dr & $21 / 03 / 2018$ & $34.932727^{\circ} \mathrm{S}$ & $138.539975^{\circ} \mathrm{E}$ & Main repair & 22-Mar & $300 \mathrm{~mm}$ & 1965 & Drinking water \\
\hline & Adelaide Airport SA 5950 & Mr Dondur by & $21 / 00 / 2010$ & ग4. & | & Mamepail & $2 z-1018$ & Sovirin & 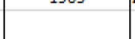 & Doming wret \\
\hline & $.34 .932727,138.539975$ & & & & & & & & & \\
\hline & 17-29 Jetty Rd & Jetty road, Comercial road & $21 / 03 / 2018$ & $35.01705^{\circ} \mathrm{s}$ & $138.51986^{\circ} \mathrm{E}$ & Main leak & $21 / 03 / 2018$ & $100 \mathrm{~mm}$ & 1962 & Drinking water \\
\hline & Brighton SA 5048 & & & & & & & & & \\
\hline & $-35.017042,138.520280$ & & & & & & & & & \\
\hline & Montague Rd & Ingle farm, Nelson road & $15 / 03 / 2018$ & $34.82963^{\circ} \mathrm{S}$ & $138.66179^{\circ} \mathrm{E}$ & Burst water main & $16 / 03 / 2018$ & $375,525,1000$ & $1963,2012,1995$ & Drinking water \\
\hline & Ingle Farm SA 5098 & & & & & & & & & \\
\hline & $-34.829606,138.661372$ & & & & & & & & & \\
\hline & 330 Gorge Rd & & & & & & & & & \\
\hline & $\begin{array}{l}\text { Atheistone SA } 5076 \\
-34.870568,138.701372\end{array}$ & Gorge road, Athelstone & $8 / 03 / 2018$ & $34.89949^{\circ} \mathrm{S}$ & $138.65720^{\circ} \mathrm{E}$ & Pipe repair & completed on $9 / 3 / 18$ & $150 \mathrm{~mm}$ & 1970 & Drinking water \\
\hline
\end{tabular}

Fig. 4 An example of the research Excel database

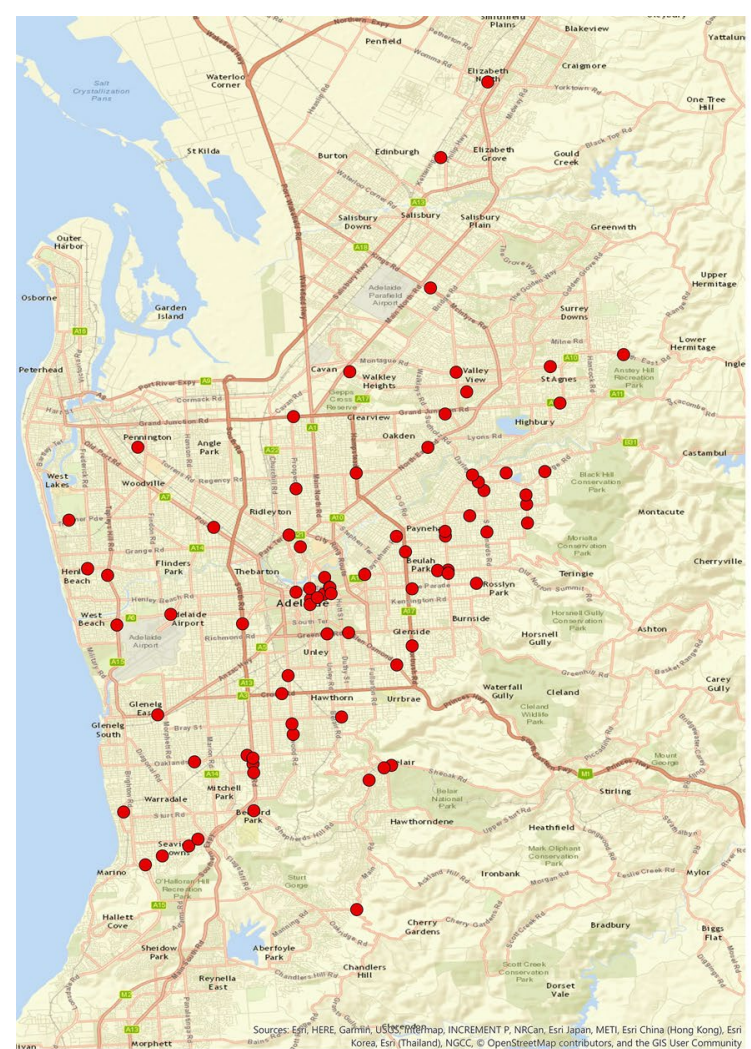

(a)

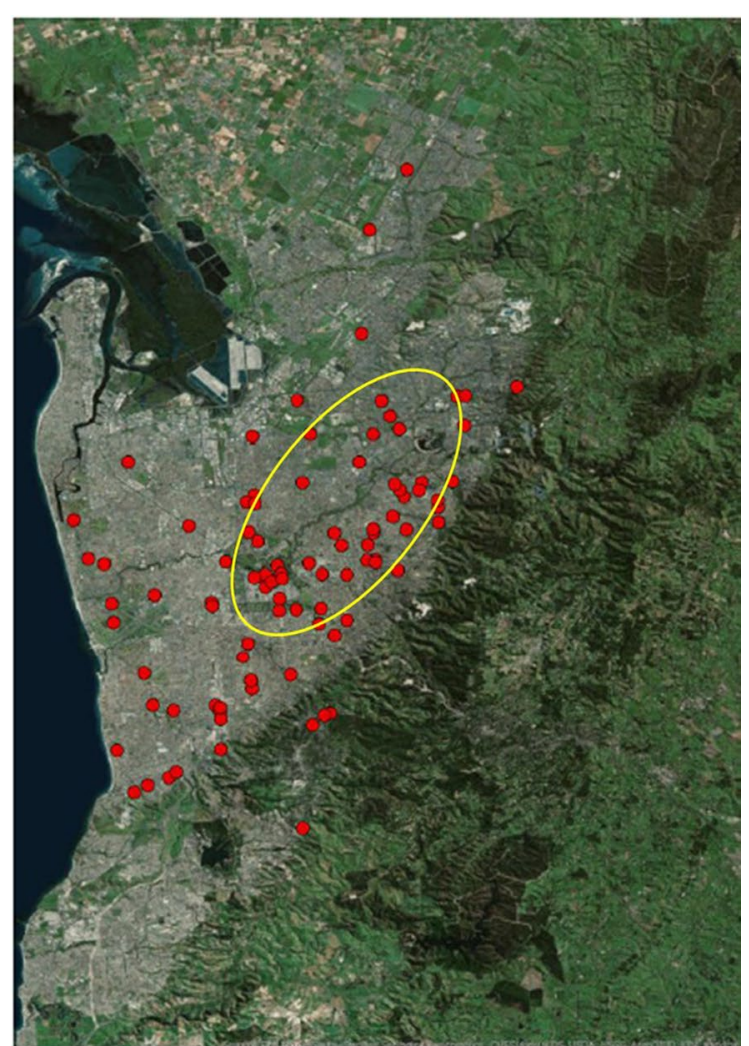

(b)

Fig. 5 a Failure locations on the Adelaide Map and $\mathbf{b}$ imagery format with labels of the 123 data points under consideration (yellow circle shows the majority of data points located in the Adelaide metropolitan including the CBD and North East of Adelaide) 


\subsection{Locations (data points) on the soil layer map with soil classification}

A new map was created with two layers of data points. The soil map after applying the new "Symbology" would be an active map that can show all the soil data when clicked the point on the selected layer (Fig. 6).

Buried water pipes are restrained from movement by frictional resistance between the pipe and soil [13]. Most pipes failed during the cold and wet winter season which caused clayey soil to expand, but they also failed during the hot dry summer when the clayey soil shrunk due to the reduction in water content. As the water pipe is buried underground, tensile stresses within the pipe can be induced if it is in contact with clayey soil which is more expansive and reactive to the water content. These changes of soil condition cause movement that exerts stresses on pipes and cause failure [16]. Mordak and Wheeler [20] analysed data from four water utilities in the United Kingdom, three of these networks are in sandy and gravelly soil and the other is in clayey soil. They found that over $60 \%$ of the failures happened during the summer, i.e. in July, August and September, for the pipes buried in clayey soils. This is because clayey soils expand with an increase in water content after a dry summer and exerts extra pressure on buried water pipes.

The map in Fig. 6 is colour coded with each colour indicates a soil code. From Fig. 6 , the dominant soil code in this research is "Red Brown" soil. Red-brown soil can be grouped as RB2, RB3 and RB5 which all have the same characteristic of a clayey soil. Figure 6 shows the concentration of data points in the yellow area, where the dominant soil codes are RB3 and RB5 (Table 1).

According to the soil characteristics stated in Table 1, RB3 and RB5 are expansive soils which are very reactive to the change in water content. In this case, rainfall can be very important in relation to the water content level and corresponding soil behaviour. The rainfall changes water content in clayey which causes soil movement due to swelling and the extra stress on pipes. The above can explain the observation of many failures in orange and yellow sections of the map. Those areas such as Adelaide $C B D$, North East and a small section in the South West are the main focus of this observation.
Fig. 6 Soil code layer information. Red: RB3, RB5, Yellow: RB3, RB4, Brown: RB5

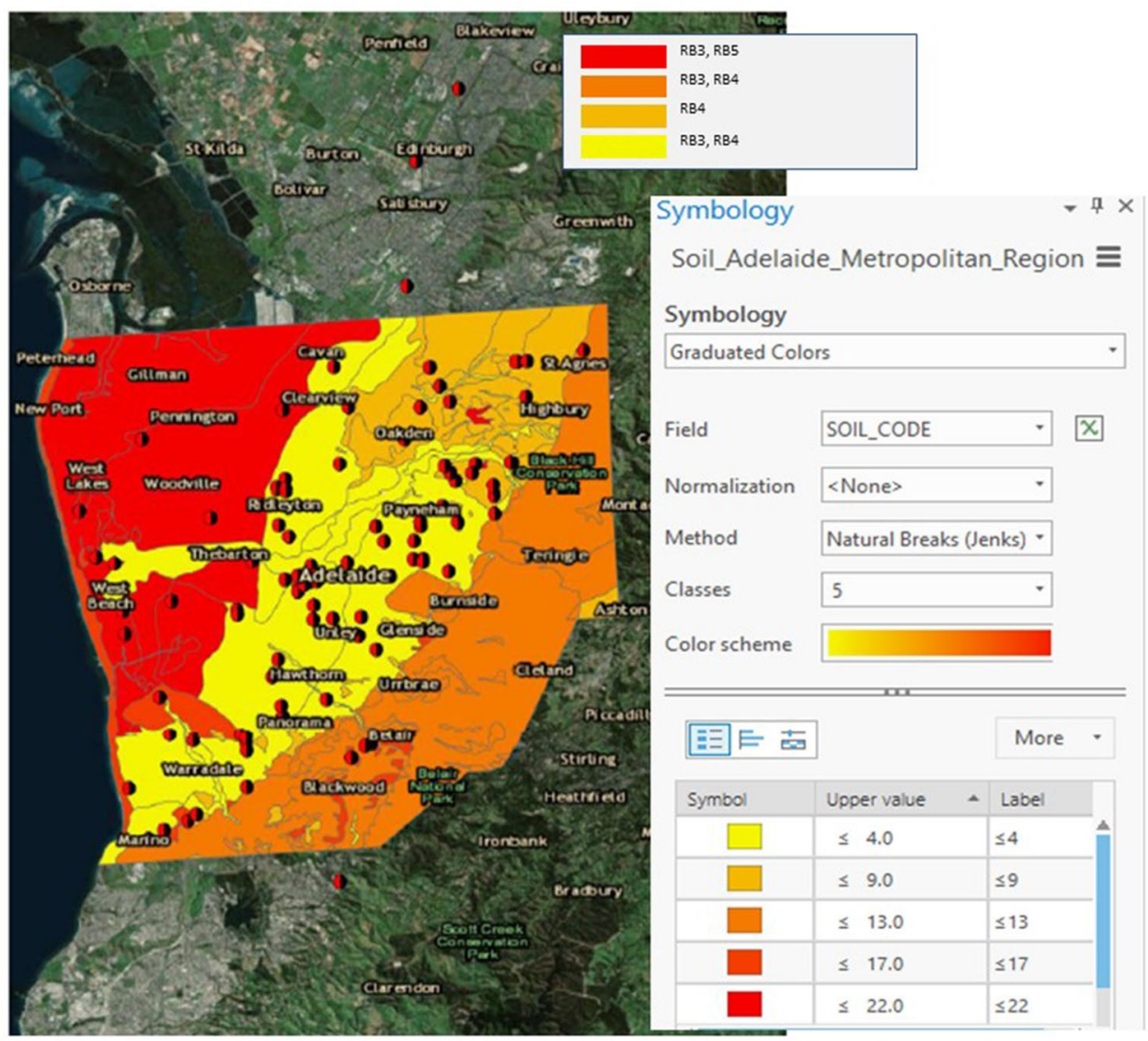


Table 1 Soil description [24]

\begin{tabular}{lll}
\hline Group & Soil type & General description \\
\hline $\begin{array}{l}\text { RED-BROWN } \\
\text { EARTHS }\end{array}$ & RB1 & Shallow stony red-brown clay soils overlying bedrock \\
& RB2 & Red-brown sandy clay soils with granular structure \\
RB3 & Heavy red-brown clay soils with prismatic or blocky structure over clay with variable lime \\
RB4 & Shallow red-brown clay soils with thin lime or calcrete layer on calcareous bedrock \\
RB5 & Red-brown clay soils with granular structure over clay with variable lime \\
& RB5a & Brown clay or sandy clay soils with granular structure over sandy clay with some lime \\
& RB3a & As for RB3 but with stone fragments throughout the profile \\
& RB3b & As for RB3 but with deep coarse-textured surface soil \\
& RB6 & Red-brown clay or sandy clay soils with blocky structure with low lime sand increasing with depth \\
RB7 & Red-brown sandy clay soils with granular structure and with low lime overlying sand \\
& RB8 & Red-brown clay soils overlying calcareous clays on rock \\
& RB9 & Mottled silty clay over brown silty clay with granular structure, slight lime, becoming sandy with depth \\
&
\end{tabular}

\subsection{Analysis of failures according to pipe diameter and installation date}

According to Rajani et al. [13], a decrease in pipe diameter could increase the frequency of pipe failure. Generally, large-diameter mains tend to fail less frequently compared to their smaller diameter counterparts. Based on a study conducted by [21], the highest failure rates are in the smaller diameter categories such as $150 \mathrm{~mm}$ and $200 \mathrm{~mm}$; especially in areas with a moderate to high reactivity (shrinkage-swelling potential) of soil.

As explained in the methodology section, the results from ArcGIS have been graphed based on the attribute table; the association between the number of failures and the diameter of the pipes is shown in Fig. 7.

To enrich the data collection for this study and gain better accuracy of the results, a longer study (time) period with a wider range of pipe ages is required. The timedependent attributes with an extended time can capture the deterioration process of the pipe, and these attributes can include, age of the pipe, the number of failures, the failure rates per $100 \mathrm{~km}$ and number of service years since the last failure (Wang et al. 2013).

Figure 7a shows a clear differentiation between smaller and larger diameter pipes about past pipe failures. The number of failures becomes much less for pipes above $300 \mathrm{~mm}$ diameter, and the greatest number of the failures was recorded for pipes with diameters of $150 \mathrm{~mm}$ and $100 \mathrm{~mm}$, respectively. It confirms the observation by Hudak et al. [21] and Rajani et al. [13] that failures are more common for smaller diameters such as $150-200 \mathrm{~mm}$. The data were further analysed by normalising against the total length of each pipe diameter and calculated the number of failures per unit length of each diameter, Fig. $7 \mathrm{~b}$ shows the normalised number of failure against
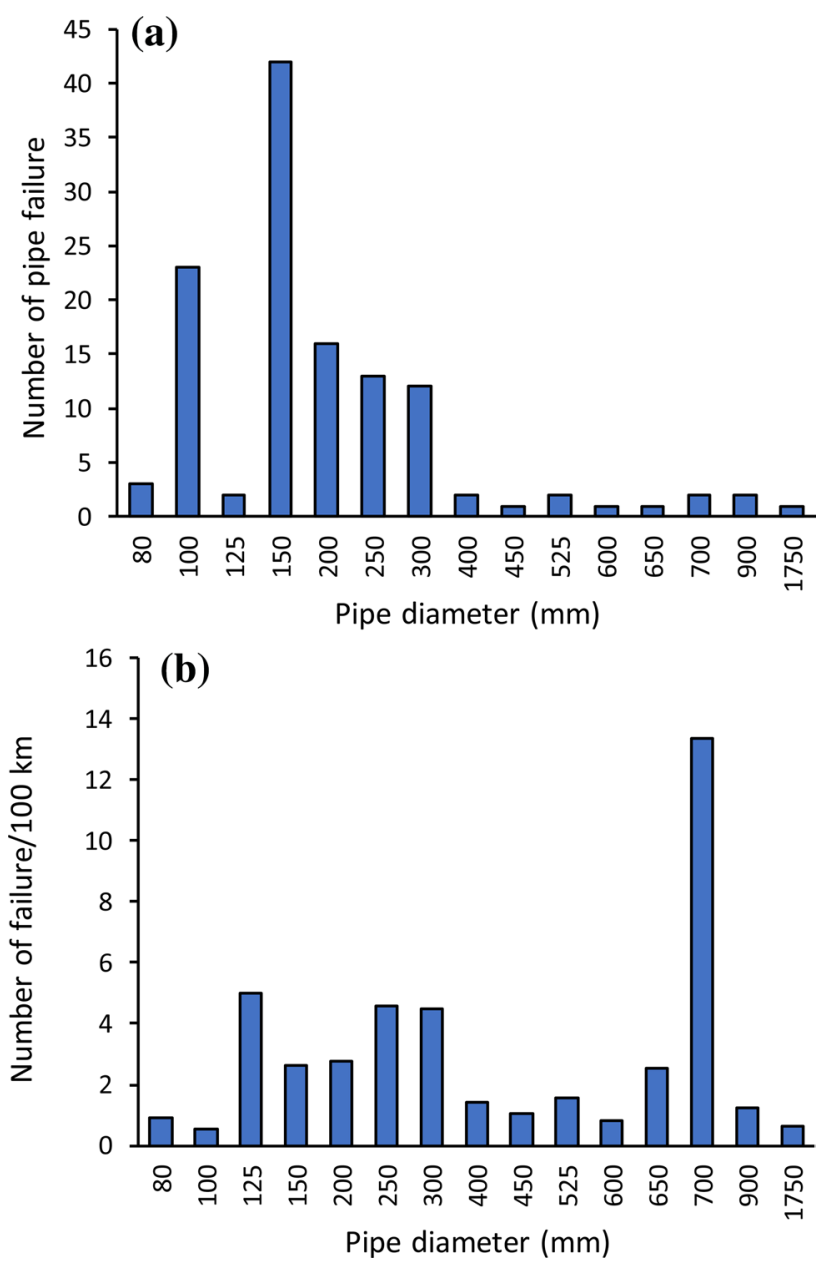

Fig. 7 a Number of failures against pipe diameter, b failure rate (number of failure/100 km) against pipe diameter 
pipe diameter supports the earlier statement that failures are more common for smaller diameter pipes, except the 700-mm pipe which showed a higher number of failure per $100 \mathrm{~km}$, this could be an outliner because of the small of failures recorded compared with the rest of the other pipe diameters.

Poor infrastructure design and installation, together with the use of inappropriate material can cause an on-going issue for pipe failure. Information about the water main history, when it was installed, which technology used, which pipe material was selected can be used to inform asset planners to prevent the selection of options with such known issues in future projects. The life expectancy of the pipe is a major parameter from an asset management point of view. Water utility assets are the most valuable assets in urban infrastructure that needs to be operated efficiently throughout their lifecycle [22]. Therefore, lifecycle cost (LCC) analysis is necessary to determine their capital and maintenance costs, and it helps to develop an asset management plan. By
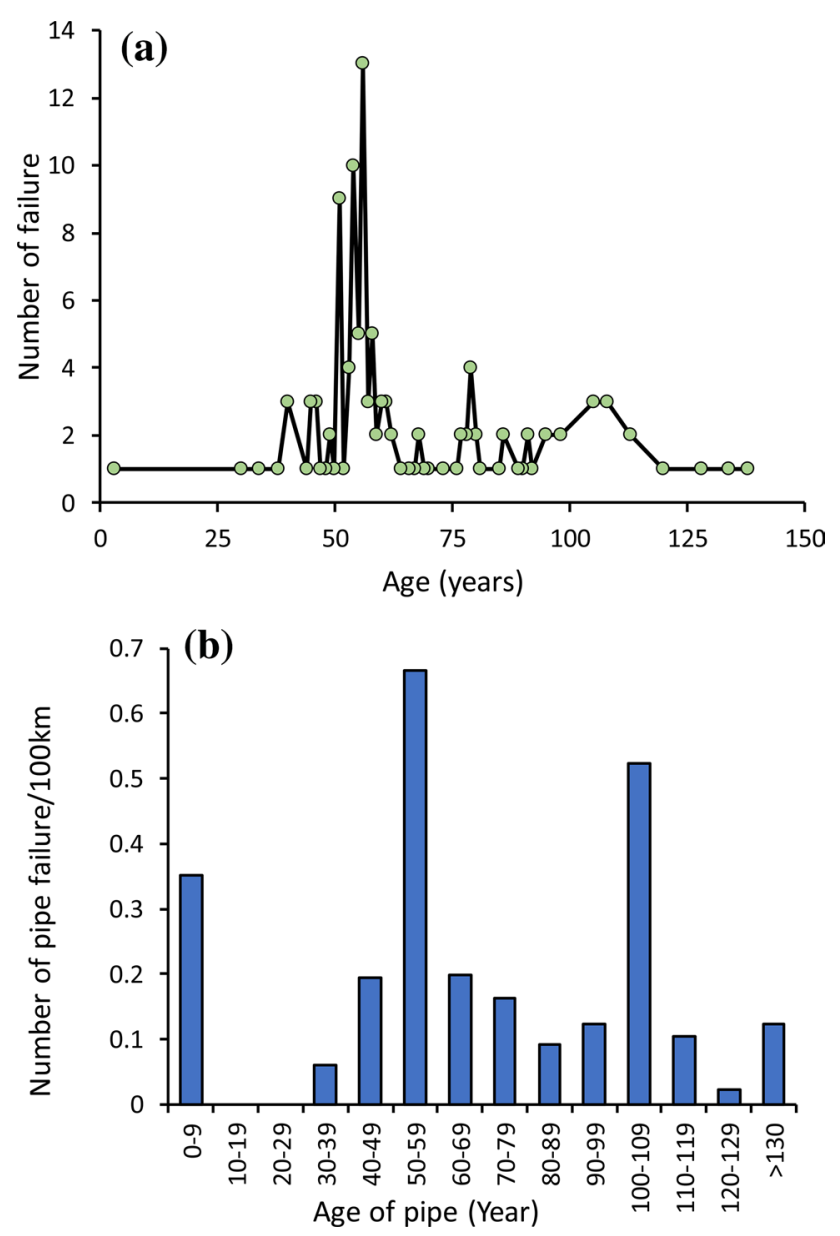

Fig. 8 a Number of failures against installation age in 2018, b failure rate (number of failure/100 km) against installation age group (10 years span)

knowing the installation date of the water mains and the end (failure) date of the same main, information can be used to determine the life expectancy of the pipe that is the key knowledge for decision-making and is curial for the water industry.

Figure 8 a shows the number of failures and the installation date (age) of the pipes. Most failures were reported for pipes installed between 1962 and 1968 which were about 55 years of age. This data set was normalised by the total pipe length of each 10 years, Fig. $8 \mathrm{~b}$ shows a plot of the number of pipe failure per $100 \mathrm{~km}$, the figure also confirmed the 50-60 year-old pipes have the most failures. When such a distinct period could be highlighted from history, a detail investigation could be launched to understand the pipe installation practices of that decade to obtain information on issues related to the failure. It could be the material of the pipe that has been supplied to the water utilities or the installation technique that has been used. But the positive impact of this study is that it gives the asset manager a good understanding of the situation that what needs to be looked at.

According to the SA Water report [14], most of the European pipes manufactured in the 1940s and 1950s, and had been installed a decade later, have already been replaced. On the other hand, the superior quality cast iron pipes constructed in the 1880 s and have been used for water mains are still in use. This shows that although this section gives us the information about the installation date of the pipes, further investigations found that installation technique was mainly unchanged, and this led to the conclusion that the pipe material is the major culprit for such a concentrated failure event.

Table 2 Number of failures recorded monthly between April 2017 and April 2018

\begin{tabular}{lc}
\hline Month & $\begin{array}{l}\text { Frequency } \\
\text { (Count) }\end{array}$ \\
\hline May 2017 & 1 \\
June 2017 & 7 \\
July 2017 & 17 \\
August 2017 & 18 \\
September 2017 & 13 \\
October 2017 & 9 \\
November 2017 & 6 \\
December 2017 & 4 \\
January 2018 & 12 \\
February 2018 & 13 \\
March 2018 & 10 \\
April 2018 & 6 \\
Total & 123 \\
\hline
\end{tabular}




\subsection{Analysis of failures based on seasonal changes and rainfalls}

Table 2 shows the number of failures in each month of the year that indicates a discernible pattern. It shows a sudden increase in pipe failures during July, August and September.

The winter months of Adelaide; June, July and August get the bulk of the rainfall while the summer months of December, January and February get a very small portion in a typical year. The spring rainfall in September, October and November are considerable, but sparse compared to the intense rainfall of the winter. For the clay form of soil; found in Adelaide's CBD and Eastern suburbs; expansion happens more often with the increase in rainfall. As the soil movement and soil reaction is highly dependent on the change in water content of the soil, it has been reported that the seasonal changes and the amount of rainfall can significantly affect the soil and pipe behaviour $[10,16]$. Therefore, to correlate water mains failure with soil water content changes, the rainfall data were essential. The rainfall data from Jan 2007 to April 2018 were collected from BOM.

The increase in water pipe failure in July, August and September 2017 (Table 2) is directly related to the significant increase in rainfall in this period (Table 3 ). This confirms the increase in pipe failure was due to soil reactivity. Similarly, there is a considerable number of failures in hot summer days in January, February and even March (in Table 2). In terms of soil reactivity in hot days with very high temperature and less rainfall, soil dries fast and shrinks, which excreted additional stress on pipe (Adelaide can experience many consecutive days with more than $35^{\circ} \mathrm{C}$ - the threshold used for the definition of heatwaves-during its summer).

\subsection{Pipe replacement program}

Many of the asset management models to predict pipe failure were developed based on historical failure data; since statistical models rely on long-term observation; they have limitations in use for new assets or assets that do not have enough historical data. Therefore, a better model should be developed based on the pipe characteristics and their behaviour through a specific time frame. In practice, water utilities should update their data system as assistance for failure prediction at least once a year and preferably end of each year after all available data were collected. If made available, the database can be used to rank all the pipes according to their failure risks for the following year to decide a replacement plan [8].

Another important part that needs to be considered in asset management is the data collection process for multiple purposes that can be shared later amongst other water service providers. It is a waste of effort to duplicate the data resources and using them for just a short project and then store them in the utility's own local server while these data can be very useful in some other projects [23]. The results of this research are compared with the SA Water's asset replacement program as discussed below.

As illustrated in Fig. 9, there is a considerable similarity between the water mains replacement program of SA Water and the areas picked by this research as critical from a failure perspective. The highlighted areas are the Adelaide CBD, North East suburbs and a small portion in the South. This research has highlighted the same focus areas, and the majority of the data points are located at the same locations as the SA Water pipe replacement program. This similarity confirms that the result of just 123 failures analysed for a period of one year provides a useful guide for prediction of pipe failures. Therefore, a study considering
Table 3 Annual rainfall data in $\mathrm{mm}$. Adapted from (Bureau of Meteorology 2018)

\begin{tabular}{rrrrrrrrrrrrrr}
\hline Year & Jan & Feb & Mar & \multicolumn{1}{c}{ Apr } & \multicolumn{1}{c}{ May } & Jun & Jul & Aug & Sep & Oct & Nov & Dec & Annual \\
\hline 2007 & 70.8 & 1.4 & 34.5 & 147.6 & 85.4 & 123.1 & 127.6 & 37.5 & 45.4 & 32.0 & 44.9 & 50.8 & 801.0 \\
2008 & 11.9 & 6.3 & 21.9 & 66.1 & 117.5 & 41.5 & 155.4 & 152.7 & 28.8 & 23.6 & 13.5 & 42.1 & 681.3 \\
2009 & 1.4 & 0.4 & 43.9 & 100.7 & 103.4 & 88.2 & 178.8 & 82.7 & 102.5 & 44.6 & 61.6 & 25.0 & 833.2 \\
2010 & 24.6 & 7.6 & 34.4 & 73.6 & 100.6 & 125.8 & 82.4 & 181.4 & 108.2 & 43.8 & 32.8 & 102.8 & 918.0 \\
2011 & 21.8 & 59.2 & 111.4 & 24.0 & 112.0 & 60.3 & 138.8 & 118.9 & 75.4 & 49.4 & 32.8 & 31.0 & 835.0 \\
2012 & 24.0 & 29.5 & 86.7 & 51.0 & 112.6 & 210.4 & 100.6 & 99.0 & 42.4 & 31.2 & 17.4 & 19.0 & 823.8 \\
2013 & 18.6 & 20.0 & 24.2 & 54.2 & 86.8 & 117.4 & 182.4 & 146.2 & 77.8 & 43.4 & 13.0 & 23.2 & 807.2 \\
2014 & & 85.0 & 34.2 & 50.4 & 92.4 & 156.0 & & 30.6 & & 14.4 & 40.4 & 7.8 & \\
2015 & 56.0 & 0.2 & 18.8 & 119.4 & 120.2 & 46.2 & 121.2 & & 51.0 & 13.4 & 20.4 & 16.0 & \\
2016 & & 9.0 & 47.8 & 13.4 & 160.6 & 146.6 & 172.6 & & 225.4 & 132.4 & 52.8 & 93.6 & \\
2017 & 59.4 & 38.8 & 21.8 & 53.6 & 74.0 & 16.2 & 160.0 & 150.6 & 110.0 & 35.2 & 37.4 & 39.0 & 796.0 \\
2018 & 15.6 & 10.4 & 8.8 & 61.8 & & & & & & & & & \\
\hline
\end{tabular}

(i) 2017 February and March-less rainfall

(ii) 2017 July and August-more rainfall 


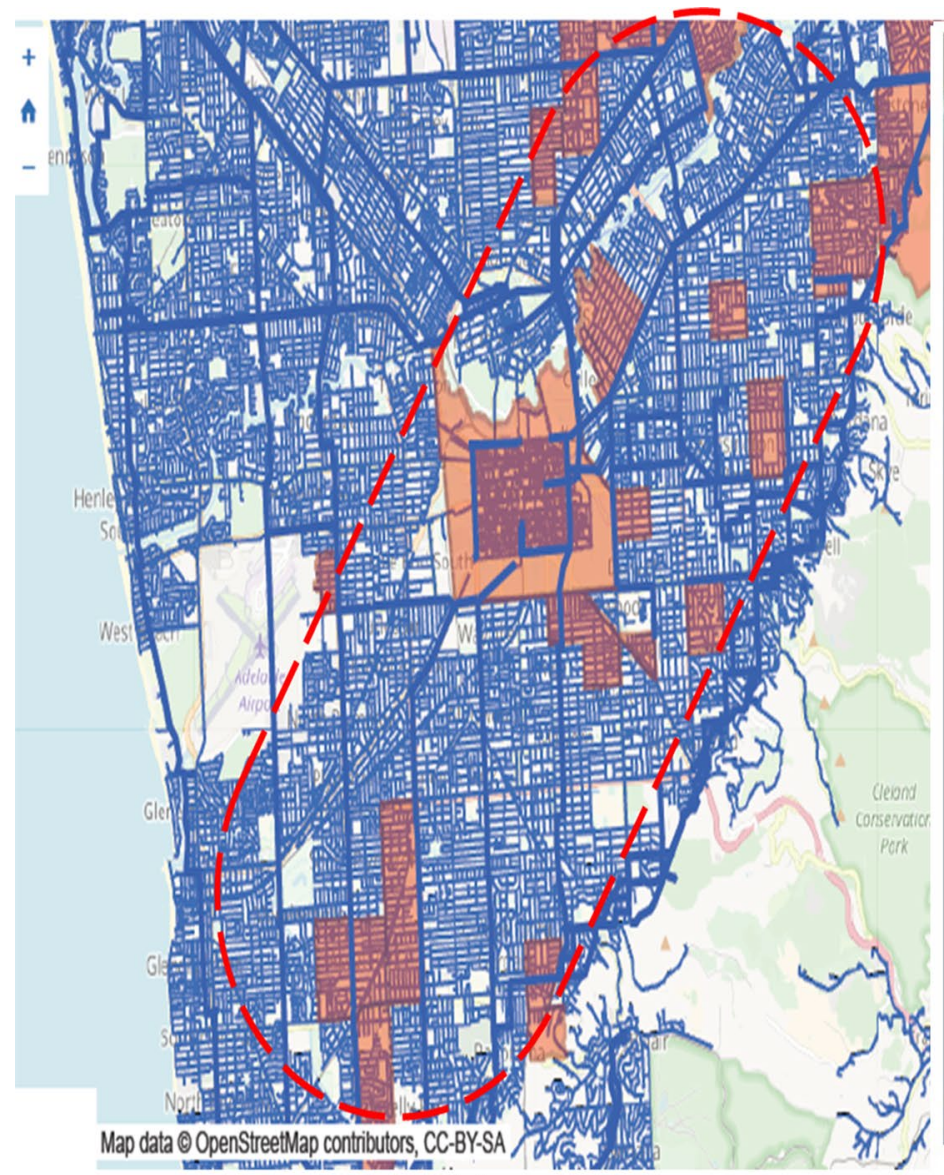

(a)

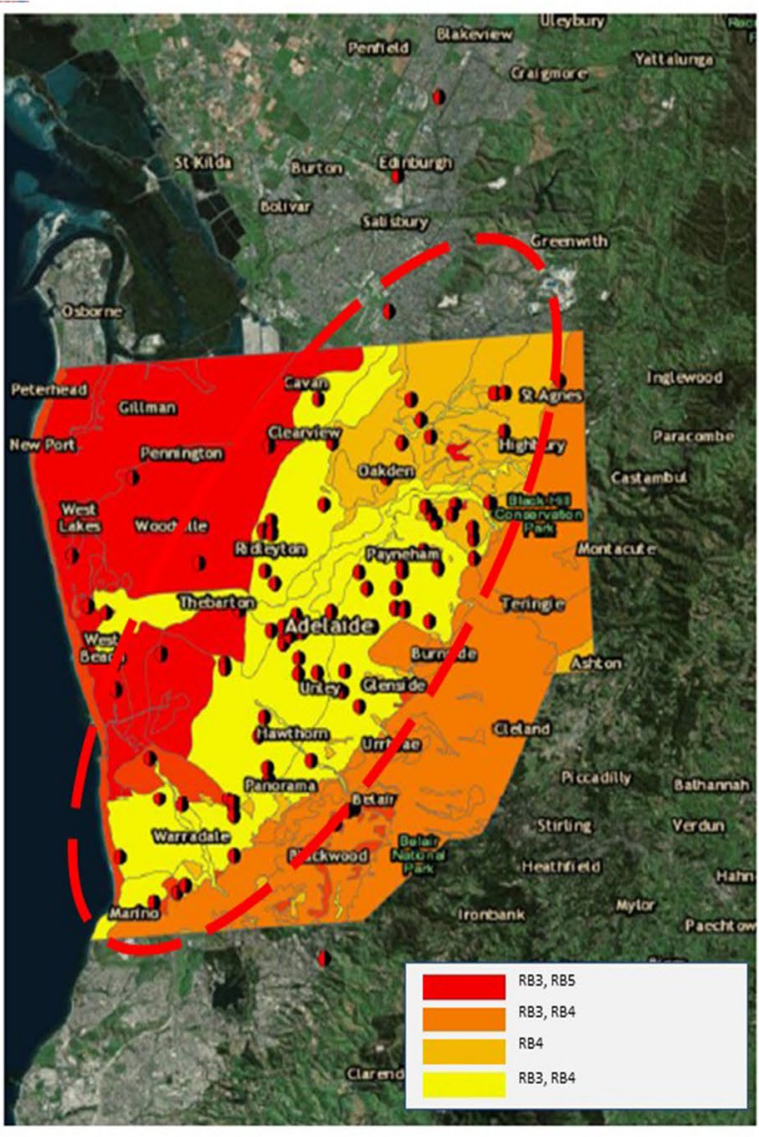

(b)

Fig. 9 Comparison of SA Water plan and the results of this research

a longer period would provide a wealth of information and increase the predictive capability.

There are minor differences between the observed failure patterns in this study and the SA Water renewal program (Fig. 10a). For example, in a larger scale map of Eastern suburbs, it can be noticed that there are some areas such as Valley View, Holden Hill or Newton which has not been considered as priorities in the next replacement plan. Although there were a considerable number of pipe failure occurred in the past (Fig. 10b and c).

\section{Conclusions}

The use of open access data can be another reliable data source for asset managers to plan pipe replacement, renewal and repair programs of their water utilities. This approach provides an effective and efficient option to obtain crucial data with less dependencies on individually managed and maintained corporate systems (databases and software) which are very expensive to maintain and the need for duplicating some databases for in-house storage. This also allows researchers or academics to conduct their own study to enrich the knowledge in the field by conducting their own study.

The approach of data analytics allowed the project team to be able to identify the data sources critical to water asset management. Through the domain expert knowledge, the information was analysed, and the potential relationships between sources of data were specified. A wide range of factors have been assessed and to be able to provide a reliable and comprehensive database for pipe failures in a region. By considering all related factors, the pipes in each zone would be categorised by their characteristics and can be linked to the environmental factors (such as soil reactivity) in a more logical manner. Most of the urban buried pipes are affected by local environmental condition, such as surface landscaping, drainage, etc.

The environmental factors related to pipe failures have been identified and can be used to predict future pipe failures (at least locate an area of hot spots). This predictive ability is extremely useful in supporting decisions for

\section{SN Applied Sciences




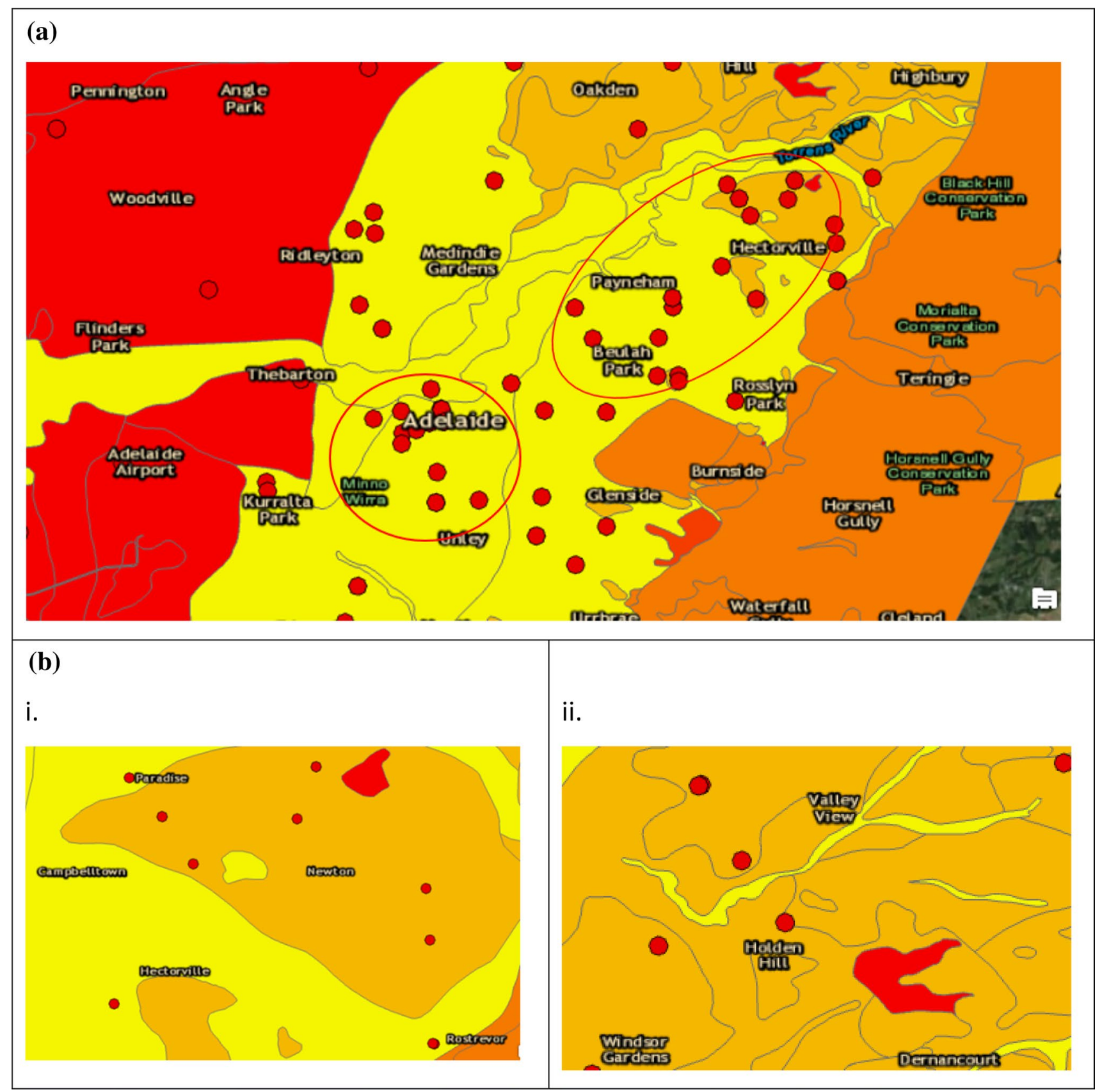

Fig. 10 a Concentration of data points in eastern suburbs and $\mathbf{b}$ next priority suburbs in the replacement program

the pipe management program of a water utility. This can lead to the development of an asset management decision support tool for pipe renewal, replacement and repair. As a result, a framework can be developed to describe, and cross-link water-related data based on the analysis of these investigations and potential relationships.

Ranking pipes according to their failure probability can help to manage the assets in a system and allocate the budget for repair or renewal activities more effectively. These approaches can be based on statistical features or dynamic features of each pipe and the outcome should be analysed and interpreted with appropriate data analytics technique or software. It graphically shows the trends and the behaviour of the main failures and by referring to reliable public access data sources could assist in planning preventive actions.

Prior to conducting this research project, the research team was sceptical about the feasibility of this proposal/ approach; specifically, whether a reliable assessment could be carried out by using open access data to determine and 
identify the factors related to water main failures. However, at the end of the project, the goal has been achieved with great success. The good outcomes of this project can be linked with SA Water's approach of establishing a customer-based inquiry platform, and this platform is linked to its asset management system. This platform could be used along with other open data sources for asset planning decisions. The authors understand this short study could be extended into further research by extending the duration of the study period under scrutiny as well as combining with one or two other interstate water utilities who could have different circumstances (operations conditions) to provide additional data to assess the impact of environmental factors on pipe failure and explore future opportunities to further promoting the use of open access data.

Acknowledgements The authors would like to thank SA Water for providing advice throughout this Project. With special thanks to Amanda Mussared and Jack Nelson, SA Water and James Kollaris, Paul Hondrovasilopoulos and Peter Vrettis, University of South Australia.

\section{Compliance with ethical standards}

Conflict of interest The authors declare that they have no conflict of interest.

\section{References}

1. Bruaset S, Rygg H, Sægrov S (2018) Reviewing the long-term sustainability of urban water system rehabilitation strategies with an alternative approach. Sustainability 10:1-30. https:// doi.org/10.3390/su10061987

2. Chik L, Albrecht D, Kodikara J (2017) Estimation of the shortterm probability of failure in water mains. J Water Resour Plan Manag 143:04016075. https://doi.org/10.1061/(ASCE)WR.19435452.0000730

3. St. Clair AM, Sinha S (2012) State-of-the-technology review on water pipe condition, deterioration and failure rate prediction models! Urban Water J 9:85-112. https://doi.org/10.1080/15730 62X.2011.644566

4. Tscheikner-Gratl F, Sitzenfrei R, Rauch W, Kleidorfer M (2016) Integrated rehabilitation planning of urban infrastructure systems using a street section priority model. Urban Water J 13:28-40. https://doi.org/10.1080/1573062X.2015.1057174

5. Wilson D, Filion Y, Moore I (2017) State-of-the-art review of water pipe failure prediction models and applicability to large-diameter mains. Urban Water J 14:173-184. https://doi. org/10.1080/1573062X.2015.1080848

6. Boxall JB, O'Hagan A, Pooladsaz S, Saul AJ, Unwin DM (2007) Estimation of burst rates in water distribution mains. Proc Inst Civ Eng Water Manag 160:73-82. https://doi.org/10.1680/ wama.2007.160.2.73

7. Water SA (2020) Our plan 2020-24: working together to sustainably improve water services. SA Water, Adelaide

8. Wang R, Dong W, Wang Y, Tang K, Yao X Pipe failure prediction: a data mining method. In: IEEE 29th international conference on data engineering, 2013. ICDE conference pp 1208-1218. https ://doi.org/10.1109/icde.2013.6544910

9. Chik L, Albrecht D, Kodikara J (2018) Modeling failures in water mains using the minimum monthly antecedent precipitation index. J Water Resour Plan Manag 144:06018004. https://doi. org/10.1061/(ASCE)WR.1943-5452.0000926

10. Gould SJ, Boulaire FA, Burn S, Zhao XL, Kodikara JK (2011) Seasonal factors influencing the failure of buried water reticulation pipes. Water Sci Technol J Int Assoc Water Pollut Res 63:26922699. https://doi.org/10.2166/wst.2011.507

11. Kodikara J, Kuen T, Hind E (2017) An innovative integrated algorithm for cost-effective management of water pipe networks. Departments of Civil Engineering, Monash University, Melbourne

12. Nicholas MS (2007) An analysis of water main failures in metropolitan adelaide. SAWater, Adelaide

13. Rajani B, Zhan C, Kuraoka S (1996) Pipe-soil interaction analysis of jointed water mains. Can Geotech J 33:393-404. https://doi. org/10.1139/t96-061

14. AWA (2018) Water main burst. http://www.awa.asn.au/AWA MBRR/Branches/SA/Recent_events/Water_main_bursts.aspx. Accessed 052018

15. Chan D, Gallage CPK, Rajeev P, Kodikara J (2015) Field performance of in-service cast iron water reticulation pipe buried in reactive clay. Can Geotech J 52:1861-1873. https://doi. org/10.1139/cgj-2014-0531

16. Hu Y, Vu HQ (2011) Analysis of soil conditions and pipe behaviour at a field site. Can Geotech J 48:847-866. https://doi. org/10.1139/t11-010

17. Kim AE, Hansen HM, Murphy J, Richards AK, Duke J, Allen JA (2013) Methodological considerations in analyzing twitter data. JNCI Monogr 2013:140-146. https://doi.org/10.1093/jncim onographs/lgt026

18. Australian Government (2018) National map. Australian Government. https://nationalmap.gov.au/. Accessed 052018

19. Government of South Australia (2018) Location SA map viewer. Government of South Australia. http://location.sa.gov.au/viewe r/. Accessed 052018

20. Mordak J, Wheeler J (1988) Deterioration of asbestos cement water mains. The Department of Environment, No.: PECD 7/7/117, Wiltshire, United Kingdom, pp 1-174

21. Hudak PF, Sadler B, Hunter BA (1998) Analyzing underground water-pipe breaks in residual soils. Water Eng Manag 145:5

22. Francisque A, Tesfamariam S, Kabir G, Haider H, Reeder A, Sadiq $R$ (2017) Water mains renewal planning framework for small to medium sized water utilities: a life cycle cost analysis approach. Urban Water J 14:493-501. https://doi.org/10.1080/15730 62x.2016.1223321

23. Jin H, Stringer G, Aryal R, Gorjian N, Chow CW, Conference AsIW, exhibition Sydney A-M (2017) Metadata framework: building a data platform for asset management decision support. Australia

24. Sheard MJ, Bowman GM (1998) soils, stratigraphy and engineering geology of near surface materials of the Adelaide plains. Mines and Energy South Australia, Adelaide

Publisher's Note Springer Nature remains neutral with regard to jurisdictional claims in published maps and institutional affiliations. 